\title{
Indocyanine Green Fluorescence Image-guided Laparoscopic Hepatectomy Enabled Resection of a Tumor Invisible With Ultrasonography
}

\author{
KEISUKE OURA ${ }^{1}$, TAKESHI AOKI ${ }^{1}$, YOSHIHIKO TASHIRO ${ }^{1}$, KAZUHIRO MATSUDA $^{1}$, TOMOTAKE KOIZUMI ${ }^{1}$, \\ TOMOKAZU KUSANO ${ }^{1}$, YUSUKE WADA ${ }^{1}$, HIDEKI SHIBATA ${ }^{1}$, TAKESHI YAMASHITA ${ }^{1}$, HIROMI DATE ${ }^{1}$, \\ TOMOTAKE ARIYOSHI ${ }^{1}$, SATORU GOTO ${ }^{1}$, KIMIYASU YAMAZAKI $^{1}$, MAKOTO WATANABE $^{1}$, \\ AKIRA FUJIMORI $^{1}$, YUTA ENAMI $^{1}$, KOJI OTSUKA ${ }^{1}$, ROBERT M. HOFFMAN ${ }^{2,3}$ and MASAHIKO MURAKAMI ${ }^{1}$ \\ ${ }^{1}$ Department of General and Gastroenterological Surgery, Showa University School of Medicine, Tokyo, Japan; \\ ${ }^{2}$ Department of Surgery, University of California, San Diego, CA, U.S.A.; \\ ${ }^{3}$ AntiCancer Inc., San Diego, CA, U.S.A.
}

\begin{abstract}
Background: Ultrasonography (US) is widely used for pre-operative detection of liver tumors. However, US does not have high resolution and very small tumors, tumors located near the liver surface, or those in cirrhotic livers are often not detected. Case Report: A 47-year-old woman with a previous surgery for sigmoid colon cancer (T3N1bMO Stage $3 b)$ showed a liver tumor on the surface of segment 2 by contrast-enhanced computed tomography (CT) and gadoliniumethoxybenzyldiethlenetriaminepen-taacetic acid (Gd-EOB-DTPA) magnetic resonance imaging (MRI). However, preoperative US could not identify a tumor lesion at the same site. The most likely preoperative diagnosis was metastasis from her sigmoid colon cancer and laparoscopic liver resection was performed. Intraoperative ultrasonography (IOUS) did not identify the tumor, but it was visualized with indocyanine green (ICG) fluorescence at the surface of segment 2. Laparoscopic liver resection was performed under fluorescence guidance. Pathological examination showed a pseudotumor with negative margins. Conclusion: ICG fluorescence imaging can allow visualization of liver tumors that are undetectable on US.
\end{abstract}

This article is freely accessible online.

Correspondence to: Takeshi Aoki, MD, Ph.D., Department of General and Gastroenterological Surgery, Showa University School of Medicine, 1-5-8 Hatanodai, Shinagawa-Ku, Tokyo 142-8666, Japan. Tel: +81 337848000, Fax: +81 489653019, e-mail: takejp@med.showa-u.ac.jp

Key Words: Colon cancer, fluorescence guided, indocyanine green, liver tumor resection.
Intraoperative ultrasonography (IOUS) is widely used for observing liver anatomy, staging tumors, guiding tumor resection, and detecting additional lesions in up to $20 \%$ of patients (1). Laparoscopic liver resection has gained widespread acceptance worldwide. Many reports have shown the feasibility, safety, and benefits of laparoscopic surgery over open liver resection.

Intraoperative ultrasonography (IOUS) in laparoscopic liver resection is more important compared with open liver surgery because the information obtained by palpation using laparoscopic forceps during liver resection is extremely limited. However, ultrasonography cannot reveal tiny tumors and liver tumors near the liver surface or cirrhotic livers.

Currently, indocyanine green (ICG) fluorescence imaging is widely used in various surgical fields (2). In liver surgery, Aoki et al. reported the first demonstration of anatomical liver resection using fluorescence guidance with ICG (3), ICG fluorescence can intraoperatively identify tumors invisible with other imaging modalities (4).

In the present report we describe a case in which ICG fluorescence-guided laparoscopic resection of a tumor invisible with IOUS was performed.

\section{Case Report}

A 47-year-old woman had a surgery for sigmoid colon cancer one year previous to her presentation with a lesion in the liver segment 2 observed with contrast-enhanced CT (Figure 1A). gadoliniumethoxybenzyldiethlenetriaminepen-taacetic acid (Gd-EOB-DTPA) magnetic resonance imaging (MRI) imaging showed early ring enhancement of approximately $15 \mathrm{~mm}$ in size at segment 2, and a neoplastic lesion with reduced uptake in the hepatocyte phase (Figure 1B). Abdominal ultrasound (US) did not detect the lesions that were seen on CT and MRI. 


\section{A}

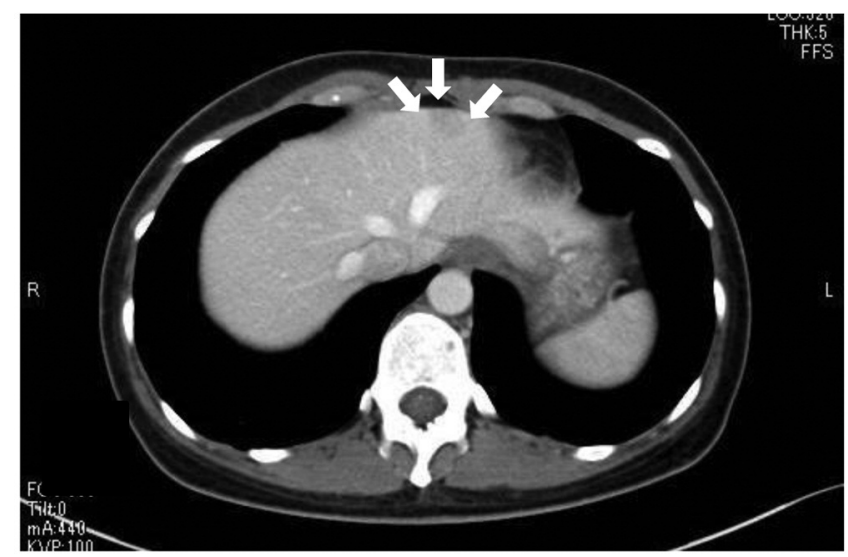

B

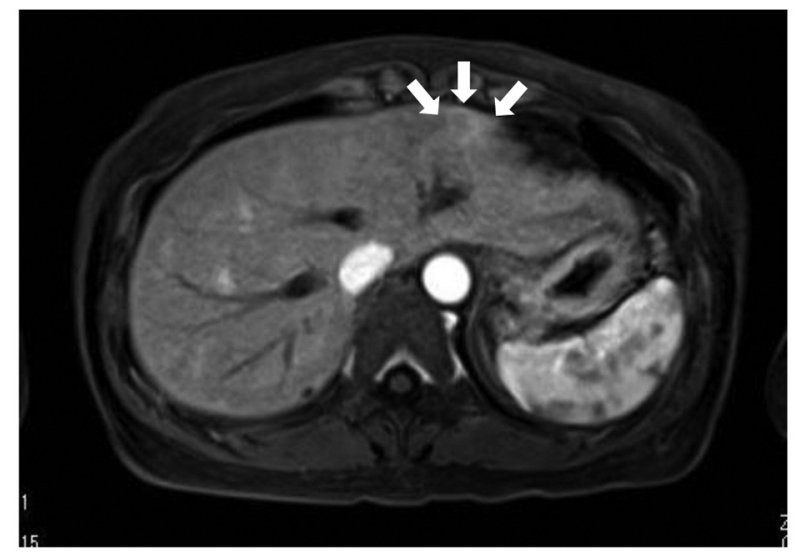

Figure 1. Preoperative computed tomography, magnetic resonance gadoliniumethoxybenzyldiethlenetriaminepen-taacetic acid (Gd-EOB-DTPA) magnetic resonance imaging (MRI), and ultrasonography image. (A) Preoperative abdominal computed tomography (CT) scan imaging. Contrast CT shows poor contrast area (white arrows). (B) Preoperative MRI EOB imaging. The neoplastic lesion in segment 2 has a ring enhancement contrast effect (white arrows).

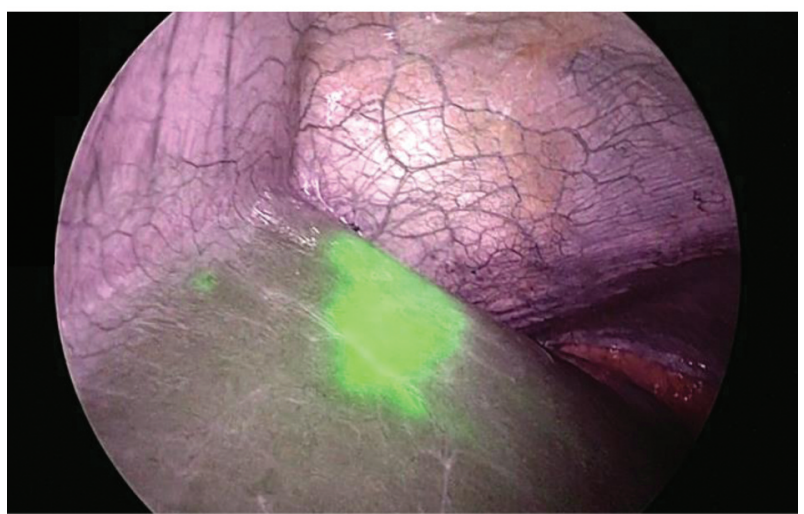

Figure 2. Intraoperative findings: a tumor in segment 2. Near-infrared fluorescence image; fluorescence was detected on the liver surface (white arrow).

No swollen lymph nodes, ascites, or peritoneal metastases were observed. The level of carcinoembryonic antigen (CEA) was $1.3 \mathrm{ng} / \mathrm{ml}$, carbohydrate antigen $19-9$ (CA19-9) was $4.0 \mathrm{U} / \mathrm{ml}$ and alpha fetoprotein was $0.6 \mathrm{ng} / \mathrm{ml}$.

Final diagnosis. The patient was clinically diagnosed with liver metastases from sigmoid colon cancer.

Treatment. Explain to the patient and obtain consent. It is also approved by the Showa University Hospital Ethics Committee. ICG $0.5 \mathrm{ml} / \mathrm{kg}$ was intravenously administered two days before laparoscopic partial liver resection. The tumor in segment 2 was invisible under IOUS. However, it was detected in the same segment by ICG fluorescence using a PINPOINT Endoscopic

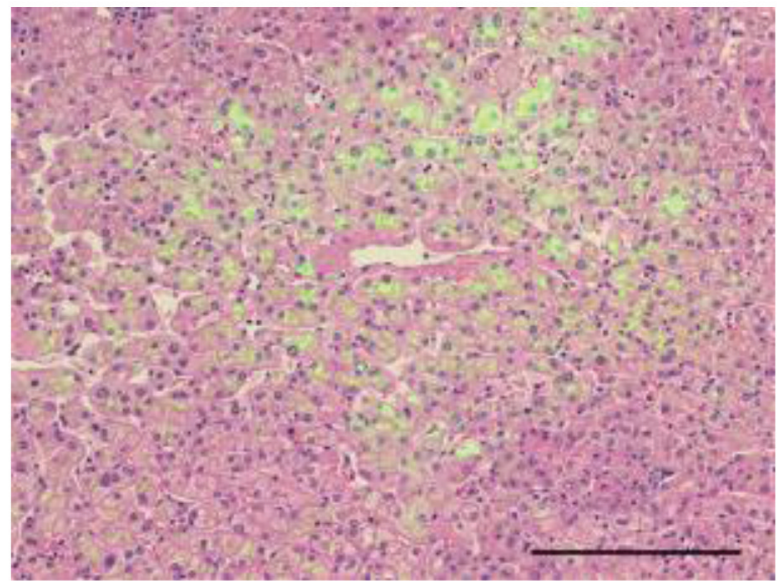

Figure 3. Macroscopic image of the tumor. Fluorescent microscopy image ( $\times 200$ magnification; bar $=200 \mu \mathrm{m}$ ).

Fluorescence Imaging System (Stryker, Kalamazoo, MI, USA) (Figure 2). Liver parenchymal transections were carefully performed under fluorescence guidance enabling the surgical margin to be secured. The operation time was $1 \mathrm{~h}$ and $58 \mathrm{~min}$, and blood loss was very small. No visible mass or nodules were observed macroscopically by ICG fluorescence on the resected surface tissue. Pathological examination diagnosed a pseudotumor which was a metastases of sigmoid colon cancer.

\section{Discussion}

Laparoscopic IOUS is a useful tool for detecting liver tumors with a performance similar to open IOUS (5). However, laparoscopic IOUS has some drawbacks, such as intrinsic 
human tremor that prevent accurate depiction of lesions, restrictive movement with only 4 degrees of freedom, and a 2-dimensional view. These drawbacks limit the utility of laparoscopic IOUS in complex liver resections and may increase the risk of not detecting small tumors.

Currently, ICG is used for fluorescence-guided surgery in various organs (2). Our team was the first report on anatomical liver section using fluorescence imaging with ICG in 2008 (3). Subsequently ICG fluorescence imaging is used for the detection of liver tumors, defining surgical margins (4), biliary tract surgery (6), and bile leakage.

ICG has a fluorescence peak at wavelength of approximately $830 \mathrm{~nm}$ when irradiated with excitation light with a wavelength of approximately $760 \mathrm{~nm}$. There are many clinical imaging systems compatible with ICG fluorescence $(7,8)$. Both colorectal cancer and hepatocellular carcinoma have been shown to accumulate ICG (9). ICG fluorescence helps to identify the tumors that cannot be identified by ultrasonography. The present study, showed the treatment of a tumor that could not be identified by preoperative and intraoperative ultrasonography. Therefore, we attempted to identify the tumor using ICG fluorescence and were able to perform complete laparoscopic partial liver resection with accurate and safe surgical margins under fluorescence guidance. Pathological diagnosis showed the tumor as a pseudotumor. Under a fluorescence microscopy, the pseudotumor showed diffuse fluorescence (Figure 3).

ICG fluorescence has some disadvantages, such as the inability of fluorescence signals to visualize tumors deeply localized below the liver surface. Furthermore, there is a high rate (about $40 \%$ ) of false positives. Based on the pathological findings, the targeted tumor in the present case was a pseudotumor, although the preoperative diagnosis was metastatic colorectal liver tumor. However, the present study showed that ICG can allow the detection of tumors in the liver that are invisible with IOUS. Furthermore ICG fluorescence has a higher detection rate for small tumors or tumors near the surface of the liver than IOUS (10). Therefore, ICG is useful for fluorescence-guided surgery of otherwise invisible liver tumors near the surface.

\section{Conflicts of Interest}

The Authors have no conflicts of interest to declare in relation to this study.

\section{Authors' Contributions}

K.O., R.M.H., and T.A performed the operation and wrote the article; Y.T., T.K., T.K., Y.W., H.S., T.Y., H.D., T.A., S.G., K.Y., M.W., A.F., Y.E., K.O., M.M. provided technical support and conceptual advice.

\section{Acknowledgements}

All Authors were involved in the editing and approval of the final manuscript.

\section{References}

1 Ferrero A, Langella S, Giuliante F, Viganò L, Vellone M, Zimmitti G, Ardito F, Nuzzo G and Capussotti L: Intraoperative liver ultrasound still affects surgical strategy for patients with colorectal metastases in the modern era. World J Surg 37(11): 2655-2663, 2013. PMID: 23974959. DOI: 10.1007/s00268-013-2183-6

2 Kitai T, Inomoto T, Miwa M and Shikayama T: Fluorescence navigation with indocyanine green for detecting sentinel lymph nodes in breast cancer. Breast Cancer 12(3): 211-215, 2005. PMID: 16110291. DOI: 10.2325/jbcs.12.211

3 Aoki T, Yasuda D, Shimizu Y, Odaira M, Niiya T, Kusano T, Mitamura K, Hayashi K, Murai N, Koizumi T, Kato H, Enami Y, Miwa M and Kusano M: Image-guided liver mapping using fluorescence navigation system with indocyanine green for anatomical hepatic resection. World J Surg 32(8): 1763-1767, 2008. PMID: 18543027. DOI: 10.1007/s00268-008-9620-y

4 Aoki T, Murakami M, Koizumi T, Matsuda K, Fujimori A, Kusano T, Enami Y, Goto S, Watanabe M and Otsuka K: Determination of the surgical margin in laparoscopic liver resections using infrared indocyanine green fluorescence. Langenbecks Arch Surg 403(5): 671-680, 2018. PMID: 29915961. DOI: 10.1007/s00423-018-1685-y

5 Viganò L, Ferrero A, Amisano M, Russolillo N and Capussotti L: Comparison of laparoscopic and open intraoperative ultrasonography for staging liver tumours. Br J Surg 100(4): 535-542, 2013. PMID: 23339035. DOI: 10.1002/bjs.9025

6 Ishizawa T, Kaneko J, Inoue Y, Takemura N, Seyama Y, Aoki T, Beck Y, Sugawara Y, Hasegawa K, Harada N, Ijichi M, Kusaka K, Shibasaki M, Bandai Y and Kokudo N: Application of fluorescent cholangiography to single-incision laparoscopic cholecystectomy. Surg Endosc 25(8): 2631-2636, 2011. PMID: 21424202. DOI: $10.1007 / \mathrm{s} 00464-011-1616-2$

7 Satou S, Ishizawa T, Masuda K, Kaneko J, Aoki T, Sakamoto Y, Hasegawa K, Sugawara Y and Kokudo N: Indocyanine green fluorescent imaging for detecting extrahepatic metastasis of hepatocellular carcinoma. J Gastroenterol 48(10): 1136-1143, 2013. PMID: 23179608. DOI: 10.1007/s00535-012-0709-6

8 van der Vorst JR, Schaafsma BE, Hutteman M, Verbeek FP, Liefers GJ, Hartgrink HH, Smit VT, Löwik CW, van de Velde CJ, Frangioni JV and Vahrmeijer AL: Near-infrared fluorescenceguided resection of colorectal liver metastases. Cancer 119(18): 3411-3418, 2013. PMID: 23794086. DOI: 10.1002/cncr.28203

9 Ishizawa T, Masuda K, Urano Y, Kawaguchi Y, Satou S, Kaneko J, Hasegawa K, Shibahara J, Fukayama M, Tsuji S, Midorikawa Y, Aburatani H and Kokudo N: Mechanistic background and clinical applications of indocyanine green fluorescence imaging of hepatocellular carcinoma. Ann Surg Oncol 21(2): 440-448, 2014. PMID: 24254203. DOI: 10.1245/s 10434-013-3360-4

10 Kose E, Kahramangil B, Aydin H, Donmez M, Takahashi H, Acevedo-moreno L, Sasaki K, Aucejo F and Berber E: A comparison of indocyanine green fluorescence and laparoscopic ultrasound for detection of liver tumors. HPB 22(5): 764-769, 2021. DOI: 10.1016/j.hpb.2019.10.005 